\title{
Development of Renewable Woodceramics Synthesized from Cashew Nuts Shell Oil
}

\section{Toshihiro Okabe ${ }^{1 *}$, Kouji Fukuda ${ }^{2}$, Akito Takasaki ${ }^{3}$, Kazuhiko Kakishita ${ }^{4}$, Yuko Nishimoto', Yoshikazu Shinohara5, Do Quang Minh6, Phan Dinh Tuan7, Ryoichi Yamamoto8}

${ }^{1}$ Department of Chemistry, Faculty of Science, Kanagawa University, Kanagawa, Japan

${ }^{2}$ Institue for Rura Engineering, National Agriculture and Food Research Organization, Ibaraki, Japan

${ }^{3}$ Shibaura Institute of Technology, Tokyo, Japan

${ }^{4}$ Polytechnic University, Tokyo, Japan

${ }^{5}$ National Institute for Materials Science, Ibaraki, Japan

${ }^{6} \mathrm{Ho}$ Chi Minh City University of Technology, Ho Chi Minh City, Vietnam

${ }^{7}$ Ho Chi Minh City University of Natural Resources and Environment, Ho Chi Minh City, Vietnam

${ }^{8}$ Yamamoto Eco Products Laboratory, Tokyo, Japan

Email: *toshihiro.okabe@gmail.com

How to cite this paper: Okabe, T., Fukuda, K., Takasaki, A., Kakishita, K., Nishimoto, Y., Shinohara, Y., Minh, D.Q., Tuan, P.D. and Yamamoto, R. (2021) Development of Renewable Woodceramics Synthesized from Cashew Nuts Shell Oil. Open Journal of Composite Materials, 11, 23-30. https://doi.org/10.4236/ojcm.2021.112003

Received: November 20, 2020

Accepted: April 9, 2021

Published: April 12, 2021

\section{Copyright $\odot 2021$ by author(s) and} Scientific Research Publishing Inc. This work is licensed under the Creative Commons Attribution International License (CC BY 4.0).

http://creativecommons.org/licenses/by/4.0/

\begin{abstract}
The international issue to be addressed towards realizing a low-carbon society is to reduce the amount of carbon-based underground reserves such as coal, petroleum, and coke, and strongly encouraged to use carbon neutral biomass-derived resources. Woodceramics is a hybrid porous carbon material composed of wood-based biomass and phenolic resin, characterized by high far-infrared emissivity and large specific surface area. Woodceramics has been studied as heating elements and humidity and gas sensors, etc. If this is applied to the inner walls of aging and grain drying furnaces for vegetables and fruits, both ripening and drying are greatly promoted and fossil fuels used in boilers can be significantly reduced. In fact, it can produce black garlic with far infrared rays using a woodceramics brick efficiently. Furthermore, as a substitute for phenolic resin, if plant-based liquefied materials from cashew nut shell oil can be prepared and can be used for manufacturing woodceramics, then all carbon neutral circulating woodceramics made from wood-based biomass is possible to manufacture. On the other hand, woodplastics is a composite material that can be made of wooden materials and plastics, and able to expect the effective use of wood-based biomass and waste plastics.
\end{abstract}

\section{Keywords}

Cashew Nuts Shell Oil, Biomass, Wood Liquefaction, Woodplastics, Woodceramics 


\section{Introduction}

The international issue addressed toward realizing a low-carbon society is to cut the amount of carbon-based underground reserves such as coal, petroleum, and coke, and to use carbon-neutral biomass-derived resources. However, if we use plant resources that can use as food or their agricultural land, it will cause global food shortages and soaring food prices. In using biomass, it is important to make effective use of biomass which discards as garbage. Vegetables and fruits can export as high added value products by aging. Usually, vegetable foods and livestock feed export after preventing them from developing and decaying and drying them to reduce the weight. In the aging and drying process, the boiler is used as the heat source. However, exports will increase as agriculture promotes. The amount of carbon dioxide generated from the boiler fuel increases. This is a global troubled species. Woodceramics (WCMs hereafter) is a hybrid porous carbon material composed of woody biomass and phenolic resin [1]-[6]. This character of the material is high far-infrared emissivity and large specific surface area. Applying WCMs to the inner walls of vegetables, fruits, and grain drying ovens greatly promotes aging and drying. So it is possible to drastically reduce fossil fuels used in boilers. WCMs has already been put on the mounting test as the inner wall material of the aging furnace, and the product application in Japan is proceeding. If it is possible to synthesize a plant-based liquefied material from woody biomass as an alternative to phenolic resin and further use it for creating WCMs, it is all possible to manufacture carbon neutral circulating WCMs based on woody biomass.

We have recently succeeded in developing technology to manufacture recycled WCMs from woody biomass. Woodplastic is a composite material that can make from wood-based materials and plastics. It is expected to make effective use of wood biomass and waste plastics. By applying biomass technology to recycling WCMs and woodplastic production technology and energy saving technology together, agricultural waste is drastically reduced. By reducing the amount of petroleum and coal used, it is expected that it will give to solving the global warming problem facing the world.

\section{Fabricatio Process of Wcms}

\subsection{How to Make WCMs [7]}

Fabrication process for WCMs is shown in Figure 1. WCMs are fabricated by sintering woody materials impregnated with phenolic resin to form glassy carbon which reinforces the fibrous structure of non-graphitizable carbon. WCMs are processable before or after sintering, so WCMs is suitable to both of mass and small productions. The structure of WCMS is porous as is characteristic of wood and the WCMs have the prominent characteristics of lightweight, hardness, corrosion resistance and heat resistance.

WCMs can be fabricated from waste wood, waste paper, saw dust and so on. Thermolysis products derived during sintering, wood tar and pyroligneous oil, 
can be used as an antibacterial agent and a medicine.

\subsection{Method for Making Wood Liquefied Matter from Cashew Nutshell}

The liquefied matter made from cashew nutshell can be used as substitute for phenolic resin. Cashew nut shell oil, wood flour and sulfuric acid are mixed at a ratio of 3:1:0.4 at $130^{\circ} \mathrm{C}$ and then the mixture heated at $150^{\circ} \mathrm{C}$ for 3 hours to prepare a wood liquefied substance.

The constituents of raw cashew nutshell oil were anacardic acid $70 \%$ to $80 \%$, cardanol $1 \%$ to $10 \%$, cardol $15 \%$ to $20 \%$, 2 -methyl cardol $1 \%$ to $5 \%$. When raw cashew nutshell oil is heated at $130^{\circ} \mathrm{C}$, The constituents were varied cardanol $75 \%-85 \%$, cardol $15 \%-20 \%$, 2 -methyl cardol $1 \%-5 \%$ by the decarboxylation reaction. The results are shown in Table 1.

\subsection{How to Make WCMs and Woodplastics Composite from Liquefied Matter}

For making wood plastic, sawdust $136 \mathrm{~g}$ and wood liquefied matter $100 \mathrm{~g}$ and hexamethylenetetramine $15 \mathrm{~g}$ were thoroughly mixed and the mixture packed in a mold and molded at $180^{\circ} \mathrm{C}$ with pressure of $0.40 \mathrm{kgf} / \mathrm{cm}^{2}$ for $30 \mathrm{~min}$. WCMs was prepared at sintering temperature of $800^{\circ} \mathrm{C}$ for holding time 3 hours with Speed of rising temperature $5^{\circ} \mathrm{C} / \mathrm{min}$.

Table 1. Raw cashew nut shell liquid (CNSL) and cashew nut shell liquid by $130^{\circ} \mathrm{C}$ heating.

\begin{tabular}{ccc}
\hline component (\%) & CNSL (Raw) & CNSL $\left(130^{\circ}\right.$ C heating) \\
\hline anacardic acid & $70-80$ & - \\
cardanol & $1-10$ & $75-85$ \\
cardol & $15-20$ & $15-20$ \\
2-methyl cardol & $1-5$ & $1-5$ \\
\hline
\end{tabular}

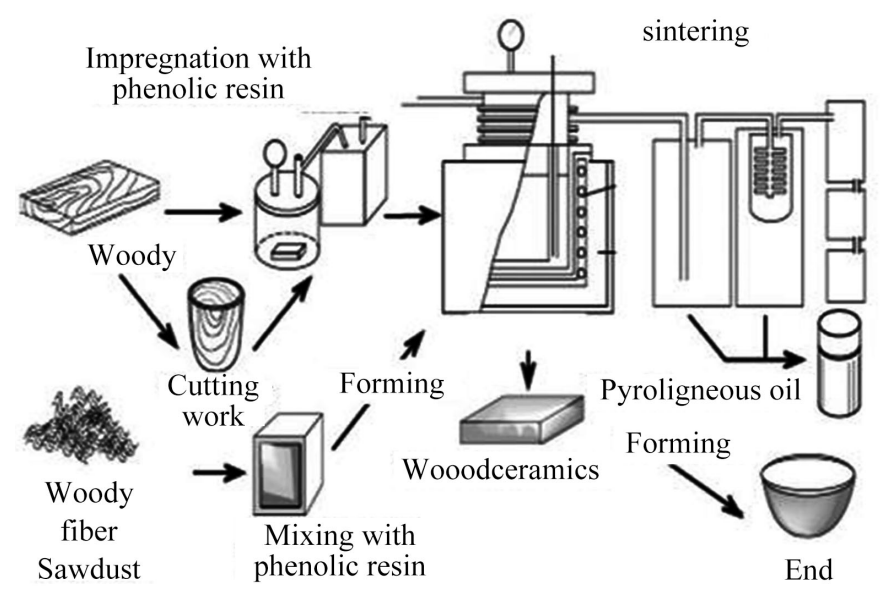

Figure 1. The manufacturing process of WCMs. 
Cashew nutshell-based liquefied materials is used for manufacturing WCMs then all carbon neutral circulating WCMs made from wood-based biomass is possible to manufacture. Cycling system of WCMs using cashew nutshell oil is shown in Figure 2.

\section{Prpperties and Applications of Wcms}

\subsection{Thermal Radiation Characteristics of WCMs [8]}

Figure 3 shows a far infrared radiation energy measuring device using FT/IR (JASCO Corporation 660 plus). Calculating the far infrared spectral ratio of far infrared black body paint (Pyromark, Tempil Inc.) instead of the black body as 0.9 . The surface temperature was measured while heating the sample with a test sample diameter of $40 \mathrm{~mm}$ and a thickness of $7 \mathrm{~mm}$, and the far-infrared spectral ratio and the far-infrared radiation energy at each temperature were measured.

Figure 4 shows the spectral emissivity at $69^{\circ} \mathrm{C}$ for WCMs sintered at $800^{\circ} \mathrm{C}$. Spectral emissivity, similar to WCMs sintered at $650^{\circ} \mathrm{C}$, was nearly $90 \%$, showing parallel radiation independent of wavelength. Figure 5 shows the spectral radiant energy at $69^{\circ} \mathrm{C}$ of WCMs sintered at temperature $800^{\circ} \mathrm{C}$.

\subsection{Aging of Black Garlic Using the Ripening Device Made from WCMs}

As shown in Figure 6, WCMs was used to prepare an aging apparatus for black garlic. WCMs with a baking temperature of $800^{\circ} \mathrm{C}$ was used. Utilizing WCMs, it became faster and aged by the far-infrared effect and moisture conditioning effect, and it became black garlic as shown in Figure 7. It was found that the state with high temperature and high humidity becomes high quality, quick and aged black garlic.

\subsection{Application of WCMs for Sensors [9] [10] [11]}

Humidity is one of the important parameter in aging and drying process, WCMs have the porous structure caused by woody fiber, so that WCMs has been developed as a humidity sensor. Humidity dependence of electrical impedance for WP-WCMs (WCMs made from waste paper; postal card) and CP-WCMs (WCMs made from cotton paper) is shown in Figure 8. It is obvious that the impedance linearly decreases with the increase of humidity in the range between $30 \% \mathrm{RH}$ to $80 \% \mathrm{RH}$.

Although a large number of polymer sensors widely used, those are limited in usage at low temperature and tend to have mold grown on the sensor surface by prolonged use. Using WCMs has an advantage of being able to avoid the mold. In addition, electrical impedance of WCMS shows linearly change to humidity, compared with logarithmically change for polymer sensors, so that the sensitivity of humidity is the same in entire measuring range. With more research, WCMs would be expected as the humidity sensors useable in aging and drying process. 


\section{Construction of the recycling society using the woodceramics}

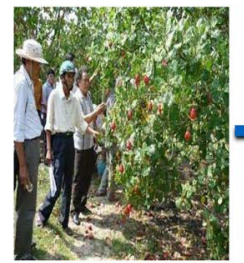

Cashew nut cultivation

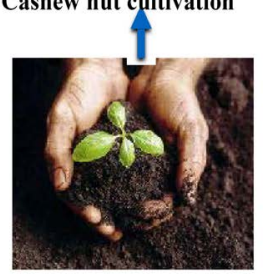

Back up in the soil

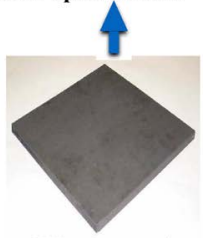

Woodceramics

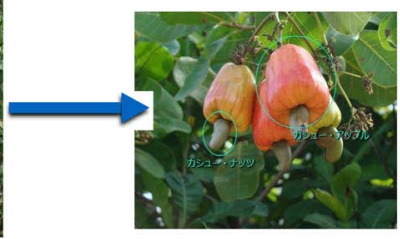

Cashew nuts apple and cashew nuts

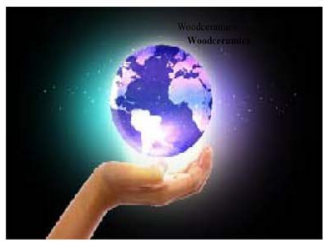

Global environment
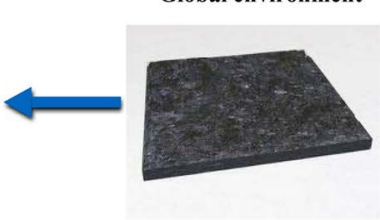

Woodplastics

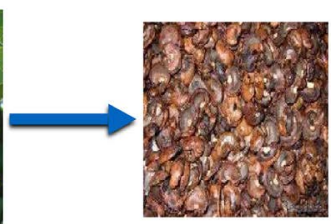

Cashew nut shell<smiles>[C+]1[CH]CCC1</smiles>

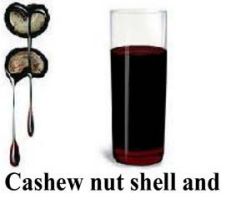

Cashew nut shell and Cashew nut shell oil

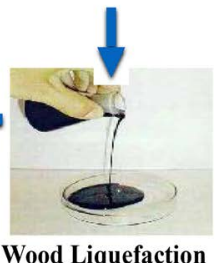

Figure 2. Cycling system of WCMs using cashew nutshell oil.

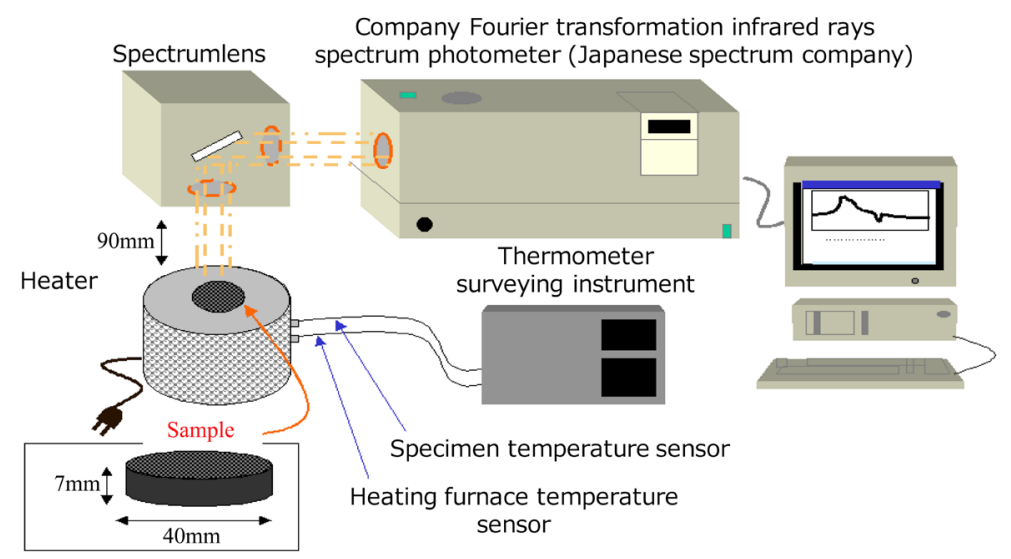

Figure 3. Far infrared ray measurement system.

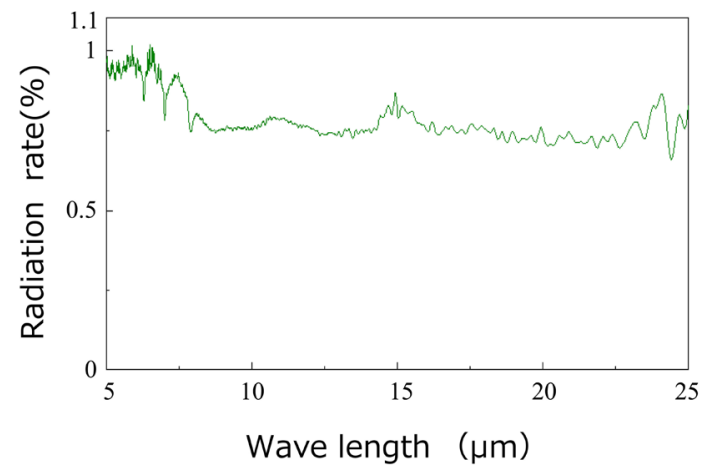

Figure 4. Spectral emissivity at $69^{\circ} \mathrm{C}$ of WCMs sintered at $800^{\circ} \mathrm{C}$. 


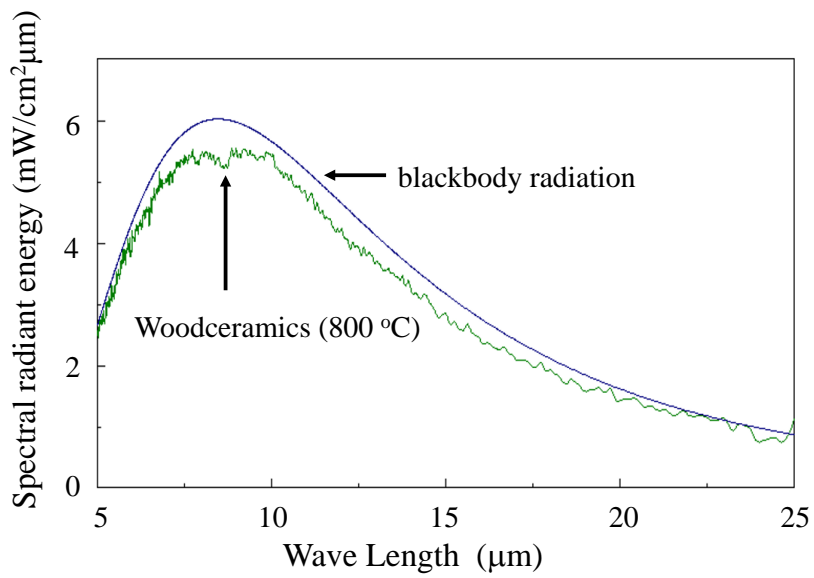

Figure 5. Spectral radiant energy at $69^{\circ} \mathrm{C}$ of WCMs sintered at $800^{\circ} \mathrm{C}$.

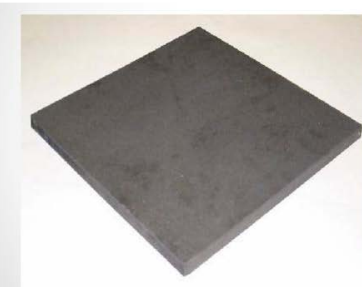

Woodceramics

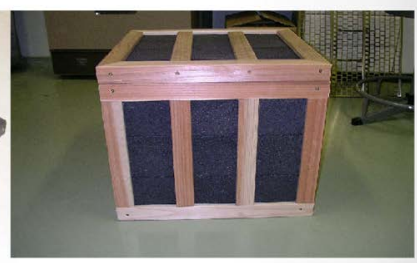

Far infrared rays container of the woodceramics

Figure 6. The ripening device using WCMs.

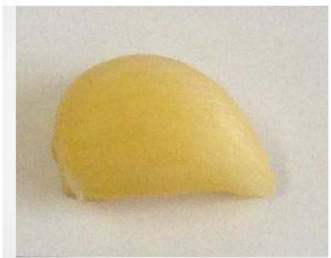

Garlic

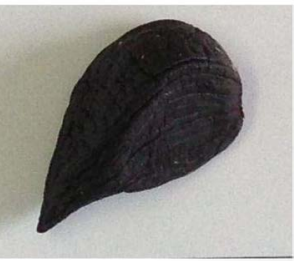

Black Garlic

Figure 7. Black garlic by far infrared heating using WCMs.

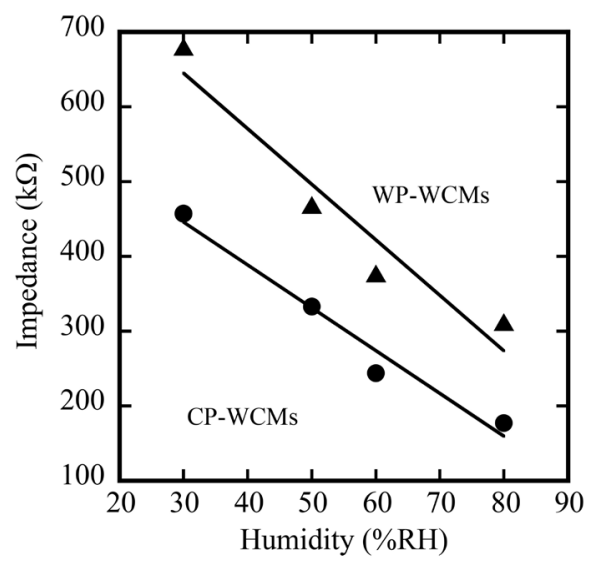

Figure 8. Humidity dependence of electrical. impedance of WCMs. 


\section{Conclusions}

1) It was able to produce wood Liquefaction using cashew nut husk oil efficiently.

2) The WCMs which we made with a plant system liquefaction thing using cashew nut husk oil emitted far-infrared rays.

3) As a result of measuring the emissivity of WCMs at a wavelength of $5.0 \mu \mathrm{m}$ to $25.0 \mu \mathrm{m}$, it was found that the WCMs emitted radiation in parallel with a spectral emissivity of about $90 \%$ without depending on the wavelength.

4) WCMs fired at $800^{\circ} \mathrm{C}$, the relation between the wavelength and the radiant energy distribution at $69^{\circ} \mathrm{C}$ was found to be that the radiant energy distribution of WCMs is close to that of the black body. As the heating temperature increases, the radiant energy also increases.

5) It can produce black garlic with far infrared rays using a WCMs brick efficiently.

6) We will be building a sustained society in the WCMs using the recycling processing technology.

7) We are going to proceed to address global warming by constructing a recycling system of WCMs using cashew nutshell oil as a future task.

\section{Conflicts of Interest}

The authors declare no conflicts of interest regarding the publication of this paper.

\section{References}

[1] Okabe, T. (1996) Wood System Carbon Material Woodceramics. Uchida Rokakuho, 42-111.

[2] Okabe, T., Saito, K. and Hokkirigawa, K. (1996) The Effect of Burning Temperature on the Structural Changes of Woodceramics. Journal of Porous Materials, 2, 215-221. https://doi.org/10.1007/BF00488111

[3] Okabe, T., Saito, K., Fushitani, M. and Otsuka, M. (1996) New Porous Carbon Materials, Woodceramics: Development and Fundamental Properties. Journal of Porous Materials, 2, 207-213. https://doi.org/10.1007/BF00488110

[4] Hata, K., Shibata, K., Okabe, T. and Outuka, M. (2000) Influence of Laser Beam Irradiation Conditions on the Machinability of Medium Density Fiberboard Impregnated with Phenolic Resin. Journal of Porous Materials, 7, 483-490. https://doi.org/10.1023/A:1009674710899

[5] Ogawa, K., Stato, M., Hata, K., Mayuzumi, M., Okabe, T., Ogawa, M. and Otsuka, M. (2005) Processing Characteristic That Uses Vibration Cutting of Woodceramics. Transactions of the Materials Research Society of Japan, 30, 1183-1186.

[6] Shibata, K., Kasai, K. and Okabe, T. (1996) Electrical Resistivity of Porous Carbon Materials, "Woodceramics" at Low Temperatures. Journal of Porous Materials, 2, 287-290. https://doi.org/10.1007/BF00489809

[7] Okabe, T. (2019) Method of Producing Carbides. JP 2015-137324.

[8] Okabe, T., Saito, K., Togawa, H. and Kumaga, Y. (1995) Development of Porous carbon Material, "Woodceramics", (II). Electromag-Netic Shielding Characteristics. 
Journal of the Society of Materials Science, Japan, 44, 284-287.

[9] Kakishita, K. and Suda, T. (2004) Application of Woodceramics for Ammonia Sensor. Transactions of the Materials Research Society of Japan, 29, 2427-2430.

[10] Mito, H., Kakishita, K., Suda, T. and Murakami, M. (2008) Application of Woodceramics as VOC Sensor. Transactions of the Materials Research Society of Japan, 33, 1221-1223.

[11] Shimizu, H., Hashimoto, K., Watanabe, N., Kakishita, K., Suda, T. and Okabe, T. (2006) Manufacture of Electrode for Polymer Electrolyte Fuel Cell with Woodceramics. Transactions of the Materials Research Society of Japan, 31, 941-944. 